\title{
Influence of Gender on Rehabilitation and Reintegration of Recidivists: A Study of Female Inmates in Women's Prisons in Selected Counties in Western Kenya
}

\author{
Okello Clifford Onyango \\ Department of Criminology \& Social Work, Masinde Muliro University of Science and Technology \\ Dr. Ombachi K. Nicholas \\ Department of Emergency Management Studies, Masinde Muliro University of Science and Technology \\ Mr. Moses Adama \\ Lecturer, Department of Criminology \& Social Work, Masinde Muliro University of Science and Technology
}

\begin{abstract}
Women were nearly never mentioned in the history of criminal justice literature, while recidivism is one of the most fundamental concepts in the field. The high rate of female recidivism having resulted in an increasing number of people being jailed and then discharged back into society, and the high risk of re-arrest, re-incarceration has become a top priority for governments, sociologists, the general public and those included in correctional facilities. The research took place at three Western Kenya women's prisons: Kakamega Women's Prison, Bungoma Women's Prison, and Busia Women's Prison. The study's overall goal was to look into the influence of gender on female recidivists' rehabilitation and reintegration. The research was based on the following precise goal; to determine the patterns of recidivism among female prisoners in selected counties in western Kenya prisons. The study used a descriptive research approach and was based on gendered route theory and relational theory. Repeat offenders from the respective jail facilities made up the research population. To acquire the desired representation from the study population, purposive selection was performed. For this study, 150 female respondents were chosen from a target population of 240 recidivists. Questionnaires and guidelines for Key Informant Interviews were utilized to collect data. The quantitative data was analyzed using SPSS version 20.0 for windows, and the qualitative data were analyzed thematically. The study emphasizes the importance of introducing alternative rehabilitation approaches such as vocational training for female recidivists having manufacturing, processing, and farming technical talents and abilities. The study provides useful information and identifies a knowledge gap that the Kenyan prisons department and stakeholders would make use of to enhance legislation and rehabilitation techniques for female inmates. Females had a greater rate of recidivism, according to the study. The survey also discovered that the available rehabilitation programs don't really match the demands of the inmates. In addition, failure by the society to accept the female ex-convicts back into the community and to offer them new opportunities for employment may result in further recidivism.
\end{abstract}

Keywords: Gender, Rehabilitation, Reintegration, Recidivists, Female inmates

DOI: $10.7176 /$ PPAR/11-8-05

Publication date:October $31^{\text {st }} 2021$

\subsection{Background to the study}

Recidivism is an essential principles or ideas in criminal justice. After obtaining punishment or being treated to intervention for a past offense, a person's relapse to criminal behavior is referred to as recidivism.(Verbrugge, P., Nunes, K., Johnson, S. \& Taylor, K. 2002).Some scholars regard it as re-apprehension, re-conviction, and reimprisonment (Benda, 2005). (Law,2004). Recidivism is defined as returning to breaking the law after already being penalized by the law, in this case, jail. Recidivism is defined by Webster's dictionary as "a tendency to revert to a former criminal pattern."

In the past, women were almost non-existent in criminal fiction. Until recently, most criminologists either ignored or relegated the issues raised by female criminality to footnotes in discussions of criminality. Women's experiences have been downplayed in these stories, and their crime has been perverted to fit whatever male explanation has been proposed. In that situation, it was considered that criminality was a male trait, hence explaining male criminality explained all criminality (Bogg 2020). However, it has come to the attention of most criminologists that the indulgence of women into criminality has its own explanations and cannot be ignored, hence bringing a challenge to researchers to research more in these areas to provide explanation for these behaviors.

The rise in female rates of recidivism in the 1990s has really been attributed to growing female engagement in substance use and the war on drugs' tough-on-crime policies. According to multiple sources, a large number of women have been incarcerated as a result of drug offenses and property offences related to their drug usage (Bloom, Chesney-Lind, \& Owen, 1994; Bloom, Owen \& Covington, 2004; Bush-Baskette, 1999; McShane \& Williams, 
2006; Owen 1998; Women's Prison Association, 2004).

As a consequence, the number of women in prison has risen dramatically, far surpassing the rise in male incarceration rates (Amnesty International Report, 2015). Women found to have lower rates of recidivism in contrast to the men globally, but the rate of female recidivism has been rising recently (Olson et al,2011). Every year, approximately 650,000 offenders are discharged from federal and state jails in the United States, with $10 \%$ of them being women. However, during days of discharge, nearly two-thirds of all freed offenders, including women, are rearrested(Durose et al,2014). During the first year of discharge, 45 percent of male inmates were arrested, whereas only 35 percent of female inmates were arrested (Alper, Durose and Markman,2018).As a result, recidivists contribute to a growing share of overall crime rates (Piquero,Jennings \& Barnes,2015).

In United Kingdom, the total number of criminals in the fourth quarter of 2016 was 114,000 of which $17 \%(19,400)$ were female. The reoffending rate for female offenders was $23.4 \%$ while that of male was $30.7 \%$ (Uk Ministry of justice,2018). According to national statistics, the total number of female inmates climbed by 108 percent between 1990 and 2000, despite the fact that the total number of male convicts has increased, by 77 percent (Harrison \& Beck, 2008). Female incarceration climbed from 47 to 64 per 100,000 population between 1995 and 2005, while male incarceration went from 789 to 925 per 100,000 (Harrison \& Beck, 2006.) Female recidivism in state and federal prisons has climbed more than eightfold, from 12,000 in 1980 to over 106 thousand by mid-2005; females now account for 7\% of the jail population, up from 6.1 percent in 1995. (Harrison \& Beck,2006).

Female incarceration has also raised concerns, particularly because it is growing at a higher rate than male incarceration (cossins 2015). According to Mangena, T. (2018), over 700,000 women were imprisoned in prisons around the world in 2017, as either the remand prisoners or as those who had been convicted or sentenced. According to Sawyer and Wagner (2019) in their report for the Prisons Policy Initiative 2019. With 219,000 female offenders under correctional supervision in 2017, the USA led the world. These were women who were both condemned and non-convicted and were held in municipal jails, federal prisons, and state prisons. According to the above data, China had 103, 766 people in pre-trial or administrative detention, plus an unknown number of others. Russian Federation $(53,304)$, Thailand $(44,751)$, Brazil $(37,380)$, Vietnam $(20,553)$, India $(18,188)$, and Mexico were the next highest $(13,400)$. The fraction of the national population varied significantly, according to the survey. According to the survey, African countries have the lowest overall female jail population, with an average rate of $2.5 \%$ per 100,000 people.

Since 2000 , Africa's overall female jail population has climbed by $15 \%$, while the overall population has expanded by 44\%. (Andrew,2009). While Africa has the lowest median jail population rate of the continents (77), it has a wide range of rates throughout its regions: the median rate in Western Africa is 52, while the median rate in Southern Africa is 188. In South Africa, there were 159,241 people in jail, with 2.6 percent $(6,125)$ of them being female and $97.4 \%$ being male (Levesque,2018).

Regardless of the fact that there are less female criminals in Africa's prisons (NIDA, 2018). there are concerns, specifically about the ever-increasing number of people who are imprisoned. While conceding that the number of female offenders oscillate and that statistics only provide an impression of the trend, the (Mangena,2018) revealed a growth in the number of sentenced female convicts in Kenya from 2,081 in 2009 to 3,762 in 2016. This corresponded to a nearly $3 \%$ increase in Kenya's total female jail population.

This is in contrast to Kenya's official prison capacity of 22,000 inmates. The large number of convicts is attributable to a growth in the proportion of re-offenders getting jailed, as per the Ministry of Interior and National Government Coordination (Stanley,2018) As a consequence, the researcher's work is an attempt to examine at this essential subject.

\subsection{Statement of the problem}

There has been increasing rate of female recidivism around the world has resulted in increasing numbers of female criminals being incarcerated and finally released back into society. To the Policymakers, criminologists, and those who work in correctional institutions are concerned about the increased likelihood of re-arrest and incarceration. (NIDA, 2018). There are increased cases of female recidivism in prisons as evidenced by Prison Fellowship Kenya, (2011) reports that reoffending rate stands at $50 \%$. This is further supported by data from Kenya National Bureau of Statistics in their Economic Survey of 2015 which indicates a growth variation of Daily Average Population (DAP) of twain male and female detainees at 6\%. However, a concern that DAP of female convicts grew by 37.2 percent in 2014 , compared to a $4 \%$ increase for male offenders. This underscores the gendered nature of incarceration rates. Further, as Taxman (2013) records, most studies on recidivism have been more on men rather than women therefore bringing a compelling reason to research this area. As a result, it's notable that there's still a strong case to be made for the gendered recidivism approach that this study wanted to highlight. Few rehabilitation studies have focused on vocational training and postsecondary programs aimed at economically strengthening criminals, with little consideration made to women's unique paths to criminality and how to address them. As a basis, the goal of this study was to investigate the influence of gender on the rehabilitation and reintegration of female offenders. 


\subsection{Research Objective}

To determine the patterns of recidivism among female prisoners in selected counties in Western region prisons

\subsection{Research questions}

What are the patterns of recidivism among female prisoners in selected counties in western region prisons?

\subsection{Justification of the study}

Academic rationale, policy justification, and philosophical explanation for the current study, which focuses on the impact of gender on rehabilitation and reintegration among female recidivists in western Kenya are presented.

\subsubsection{Academic Justification}

Recidivism particularly in women offenders is a problem that has little in terms of literature especially focusing on Kenyan context. The research yielded data that could be used to address the issue of female recidivism. Above all, the study sought to contribute to prison rehabilitation measures to catalyze an appetite for further research on female recidivism and prison rehabilitation. The findings shall thus be of significance to the academic world. In this regard, academicians will gain an understanding of the how gender influences the rehabilitation and reintegration of female offenders in the country as whole. With the rise on the numbers of recidivists in the wake of global recidivism, challenges of reintegration and other causes, the findings could provide an avenue for further analyses of the relationship between the two variables in other parts of the world. The findings obtained would also provide valuable literature for other related studies on female recidivism.

\subsubsection{Policy Justification}

The research may contribute to the Policy implementation and design by providing policy makers with a basis for designing responsive approaches and interventions required to improve the prison environment for the female offenders. Furthermore, the findings obtained would be crucial facilitating policy direction regarding ways of preventing the female recidivism. Its findings help to identify the many gaps and aspects that require attention in order to improve the rehabilitation programs available in our female jails.

\subsubsection{Philosophical justification}

Philosophical justification approaches are classified into three primary streams in research: positivist, interpretivist (constructivist), and critical approaches. The positivist method explains the current study ability to identify by arguing that the researcher examines at the study objectively, excluding the researcher from the research events that are happening. (Zukauskas et al,.2018)

In other words, the issues under investigation are beyond the permissible range of the researcher. The analyst's job under the positivist approach is to analyze the issues under inquiry as a bystander with an objective eye. However, when a researcher intends to alter the research's social landscape and become subjective, the constructivist theory must be followed. (Mohajan,2018).

The interpretivist approach is thus the philosophical polar opposite of the positivism paradigm, as it is subjective as opposed to the positivist's objective approach. The facts, as well as the problem under investigation, guide the critical approach. The study findings are the main emphasis of the critical approach. The research is 'free' in the concept that the researcher has complete control over the approach, processes, and techniques that will be used (Mohajan,2018)

\subsection{Literature Review}

The study reviewed theoretical, empirical and conceptual literature

\subsubsection{Age at time of incarceration}

Previous research has shown that recidivism and age have an inverse connection. Female adults 45 and older had lower rates of rearrests, reconvictions, and return to jail than their younger female adult colleagues, according to a three-year longitudinal study employing a large sample from 15 states (Langan \& Levin 2002). In a study of female adults released on parole between 2001 and 2003, it was discovered that female adults 45 and older had much lower recidivism rates than younger female adults (Pettit et al,. 2009). While there is evidence of an inverse association between age and recidivism, no previous studies have looked into jail readmission in different age groups of older persons (Hartnet et al,. 2012).

Researchers frequently look at jailed elder women as a single category (e.g., 50 or 55 and older). Age can also be used as a continuous variable by researchers (Huebner \& Berg, 2011). However, neither strategy adequately defines when recidivism begins to drop or how much of a decline occurs at different stages throughout a person's life; also, these strategies do not account for jailed people's hastened aging.

\subsubsection{Educational Level}

According to a research by Howell (2003), inmates with a diploma level of education or higher are less likely to return to jail than those who do not. When senior inmates were compared to younger offenders, the effect was considerably stronger (Clements, 2004). Howell (2003) discovered that convicts who received basic education were less likely to reoffend than those who did not receive basic education. 
According to studies, convicts have much lower literacy skills than people in the general community. (Greenberg, Dunleavy, Kutner, \& White, 2007). Furthermore, research has linked educational attainment to community recidivism. (Brennan, Dieterich, \& Ehret, 2009; Horney, Osgood, \& Marshall, 1995; Jensen \& Reed, 2006; O’Connell, 2003; Ulmer, 2001)

According to Parker et al,. (2003), felons in the United States who have completed high school have a $24 \%$ lower chance of returning to jail. Furthermore, those with at least two years of college education have a $10 \%$ chance of relapsing, four years has a nearly $6 \%$ chance, and postgraduate degree holders have a $0 \%$ chance of relapsing (Parker et al. 2003). This approach may be less meaningful to Jamaican males, whose opinions of the importance of education as a method of upward social mobility have been negatively affected by male privileging, according to Figueroa (2021). That is, in Jamaica, male privilege contributes to the confinement of women to the domestic realm and the informal sector, while males have access to skilled labor that often does not necessitate certification or training (Figueroa, Cobbett \& Younger 2012). As a result, some Caribbean men's educational dreams are jeopardized.

\subsubsection{Patterns of female recidivism}

The study discussed literature based on the patterns of recidivism focusing on the type of offence and the number of convictions of female offenders. These patterns are to guide the research work so as know which types of offences are very common among the female recidivists and which age brackets are affected by those offences. This can help the government in cases of policy formulation to prevent future occurrences of such offences. These patterns are discussed below:

\subsubsection{Type of offence committed}

Female convicts discharged for a property crime were more probably than female inmates freed for a drug or violent offense to be apprehended for any type of offence in united states (including violent, property, drug, or public order charges)( Bureau of Justice Statistics, Recidivism of State Prisoners Released in 2005). It should be emphasized that individuals may have been incarcerated for multiple offenses and were classified for this study based on the most severe charge for which the inmates were incarcerated: a violent, property, drug, or public order felony.(Bureau of Justice Statistics, Recidivism of State Prisoners Released in 2005). The type of offences committed will assist the researcher to draw a conclusion that will assist the government and other stakeholders to put the laws that regulate the use of drug and substance use.

\subsubsection{Number of convictions for female offenders}

A first-time perpetrator is someone who has been apprehended by the police in England or Wales and has gotten their first sentence. In 2019, 35 percent of all female offenders reprimanded were first-time perpetrators. In 2019, 13 percent of females, were admonished or imprisoned as first-time offenders for stealing offenses In the last five years, however, a larger percentage of female first-time perpetrators 5 percent in 2019.. The higher likelihood of female first-time perpetrators being punished for theft corresponds to general trend among female criminals (GoK, 2019)

\subsubsection{Principles of effective offender Rehabilitation Programmes}

A variety of concepts, including the Risk, Need, and Responsivity Principle (RNR), is linked to offender treatment in studies (Andrews et al,. 2011). Interventions under the RNR model are aimed to assist offenders in learning and changing their criminal behavior. Effective offender rehabilitation is founded on three principles, as per Andrews et al (1990), as stated in Andrews et al (2011): risk principle, need principle, and responsivity. The world's first scientifically grounded model for offender rehabilitation is the Risk-Need-Responsivity (RNR) Principles paradigm. Donald Arthur Andrews and James Bonta, two Canadian psychologists, coined the term which went into effect in 1990. The scholars' belief that correctional institutions all around the world ought to use science as a foundation for criminal rehabilitation motivated them to create "effective rehabilitation procedures."

The concept is founded on three essential aspects of offender classification: risk, need, and responsivity (RNR).The RNR model's rehabilitation viewpoint is based on a variety of assumptions regarding crime and offender attributes.

The first premise is that crime is caused by many trends of psychological and social factors. Clearly define, criminals incite crime, and as a result, individuals are more likely to break the law as a result of their contact with nature. The second claim is that treating these characteristics could lower rate of recidivism, therefore rehabilitation is important because this can change a person's behavior and prevent criminal activities. As a result, the environment can be manipulated to achieve favorable outcomes.

The third assumption says that empathetic, inclusive, and courteous human service is the only efficient approach (Blanchette \& Brown, 2006), necessitating the need for rehabilitators to have helper characteristics. These assumptions are critical to the study's success. According to the RNR model, The risk principle indicates that the severity of the rehabilitation program should be proportional to the level of danger. As a result, it shows that the larger the risk, the higher the program's intensity. As a result, high-risk criminals should be treated more aggressively than low-risk offenders. The first step in rehabilitation is to identify the risk/needs factors of offenders using validated instruments such as the Level of Service Inventory Revised (LSIR-R), which is gender neutral 
(Holtfreter \& Morash, 2008)Two types of risks are distinguished under the RNR paradigm. a) those that are relatively static, such as gender, age at the time of offending, and prior criminal history; and b) those who are already highly dynamic, such as substance abuse, pro-criminal beliefs and values, criminal associates, cognitive deficits, lack of concern and ego skills, antagonism, resentment, lack of remorse, and work status. The principles of risk/needs assessment in the RNR model is a key measure for this research. The notion that people differ in their risk of reoffending is critical to this study; as a result, it is critical to give treatment that is specific to an individual's risk variables. It can only be accomplished by determining an individual's danger and the perpetrator's needs.

The second concept, the Needs principle, states that people differ in their proclivity for deviant behavior, and that therapy for female ex-convicts would be personalized to fit every perpetrator's specific needs, which may vary (Kruttschnitt \& Gartner, 2003; Covington, 2007). For instance, an evaluation of a sexual offender may reveal challenges with relationships, loneliness, and emotional control disorders, among other things. The concept is crucial to this research because it emphasizes the significance of examining not only the offender's current demands, but also any hidden problems. The use of proven diagnostic tools to identify women's psychological requirements will ensure that they are placed in treatment programs that address all of their needs, including those that aren't immediately apparent

The responsivity principle is the RNR model's third principle. It emphasizes the need of tailoring therapy to the offenders' learning strategies and capacities (Bonta, 1995). It emphasizes the intervention method that should be appropriate for the offenders. As a result, for the style program to be quite useful, it should be centered on the offender's character, motivation, and ability (van der Knaap et al., 2016). The responsivity concept also implies that interventions should be customized to offenders' instructional methods or capacities, or take them into consideration. On balance, they said, most offenders' learning styles necessitate active, participatory methods of working and rather than a didactic style or a casual, unstructured, experiential mode. Gender-specific therapy and supervision programs have become increasingly popular. These types of programs offer comprehensive therapy and stem base to satisfy the unique needs of women Trauma counseling, drug and alcohol treatment, and referrals to auxiliary services like health care, housing, and free childcare are all available, spousal abuse treatment, employment, and other social assistance are all fundamental components of gender-responsive programs (van der Knaap et al., 2016).

Females, according to studies, abstain from crime earlier than males and commit considerably fewer crimes (Steffensmeier \& Allan 1996; Coutancea , 2011). This finding appears to be supported by data from Jamaican prison admissions, which reveal that men made up $93.1 \%$ of those admitted to adult correctional facilities in 2013. (PIOJ 2014).

In fact, around 231 males out of every 100,000 in the Jamaican population end up in prison. This could play a role in male truancy in the household. In Jamaican Society today, the essence of male absence from family relationships (Schlesinger,2013) would make it more difficult to reconcile with and remain connected to family members while incarcerated and afterward. Because women bear a bigger share of the burden of family and child parenting. They are considered to have a bigger stake in compliance than males and are 80 percent more likely to stop. In this context, treatment responsiveness emphasizes the significance of efficiently allocating offenders to programs and identifying characteristics that may affect the success of treatment services

This principle states that not all offenders will respond well to treatment. For example, perpetrators who lack motivation to reform may absolutely refuse rehabilitation by becoming resistant to therapy. Demotivation in offenders can be caused by a variety of variables including mental health issues, learning difficulties, deeply ingrained attitudes and behaviors, extensive histories of institutional incarceration, and a lack of preparedness and capacity to change behavior (Miceli, 2009). This notion is important because it encourages rehabilitators to look for ways to motivate such offenders but instead of ignoring or penalizing them for their unwillingness or resistance to treatment.

Despite its "gender neutral" label, this model's ineffectiveness poor treating female offenders' unique psychological requirements, such as low self-esteem, damaged relationships, trauma, and parental sorrow, limits its use to female offenders only ( Van Voorhis, 2013).

To conclude, the RNR paradigm of rehabilitation have been recognized in this study for establishing effective rehabilitation treatment programs for female offenders in Kenya, particularly in risk/needs analysis, tailoring treatment to an individual's needs, and rehabilitating recalcitrant offenders. However, the study reveals it important to employ a gender-specific theory, which meets the unique psychological demands of female offenders who engage in criminal conduct.

\subsubsection{Gender responsiveness of Rehabilitation Programmes}

This principle concentrates on high-risk offenders, identifies the most powerful dynamic risk variables for transformation, and uses mechanisms capable of changing fundamental criminal behavior elements (Cullen \& Gilbert 2015). It also evaluates criminogenic cognitive and affective attributes of offenders and utilizes this information to guide the selection and delivery of suitable correctional programs (Taxman \& Marlowe 2006).

It specifies that program treatments should focus on criminogenic requirements or offender inadequacies that 
are functionally linked to criminal behavior. As a result, specific demands that are significant to women have been identified. These criteria reflect the reality of female criminal behavior. Identifying certain characteristics when compared to women using theoretical frameworks as well as scientific proof research is referred to as gender unique needs. Based on contemporary information and study, many in the correctional field concur that women have different requirements than men, but the answers are the same. These women needs are either "not typically seen in men but more oftenly in women," "not typically seen in men but more frequently in women but hurt humans in distinctively individual and social aspects that should be acknowledged in current correctional assessment," or "not typically seen in men but more regularly in women but upset humans in distinctively personal and social aspects that should really be recognized in current correctional assessment." (Voorhis et al.,2013). The specific gender needs are those needs that trigger the female ex-convicts to indulge in reoffending and these are parental responsibility, low self esteem and trauma therapy related to both physical and sexual abuse. These gender needs are discussed below;

\subsubsection{Theoretical framework}

A theoretical framework, according to Darothi (2015), is necessary for comprehending aspects that may influence or be related with the identified problem. As a result, a hypothesis is a declaration of fact that can be refuted. It is a remark about a phenomenon that may be proven correct or incorrect. In light of this, the gendered pathways theory and relational theory were used in this study to explain why offenders recidivate even after being sentenced to prison

\subsubsection{Gendered Pathways theory}

The study of women's paths by Kathleen Daly (1992) is a fundamental hypothesis in female criminality. This idea not only addresses gender disparities in crime, but that also explains gender gap. Her work highlights the strategies of survival prevalent in most female offenders based on a qualitative sample provided by participants. Despite the small sample size, this study merits consideration because in gender-specific writings, it has been proven to be true (Bloom et al., 2003). Daly hypothesized five distinct paths that women take to become criminals (Daly, 1992).

Street women: Refers to women who have fled misuse and brutality and are now living on the streets. Drug usage, sex trafficking, or theft could be among the crimes that ensue.

Drug-Connected Women: This refers to the likelihood that women who use drugs may be persuaded into trafficking drugs by their lovers or relatives.

Harmed and Harming Women: Child maltreatment and/or neglect, whether physical or sexual, that leads to a criminal career.

Battered women are women who have also been assaulted by romantic partners but have not committed a crime prior to the violence. The criminality that follows is designed to help people cope and survive.

Economic Offending: Women who break the law out of avarice or socially aspirations can be classified into two groups: impoverished women who break the law to survive, and female who commit offenses out of greed or social desire. It's possible that the latter has never been abused, had an addiction, or been violent. (Brennan et al. 2021) The bulk of the above-mentioned paths are motivated by a desire to survive. The majority of female offenders have been subjected to abuse and trauma, distinguishing them from male criminals (Bloom et al., 2003). These courses represent the majority of female offenders and the realities of their lives. The applicability of this idea has been demonstrated in a number of gender responsive studies, and it is commonly utilized in the literature.

This theory is important in determining that women's gender-responsive concerns are associated to recidivism indicators directly or indirectly. Furthermore, other aspects of offender rehabilitation, such as risk and gender responsiveness of rehabilitation programs, such as dysfunctional or romantic relationships, and how these can lead to repeat offending among female recidivists. The study then used relational theory to look at how women's connections contribute to their recidivism.

\subsubsection{Relational Theory}

According to relational theory, a woman's marital status is frequently the driving force behind her criminal behavior (Covington et al., 2006). Since so much of this concept is founded on psychology, it concentrates on the distinctions between male and female crime in each of their unique types of identity development. According to Jean Baker Miller's 1976 book Toward a New Psychology of Women, a woman's relation with others is the most important factor in her development. Based on this research, relational theory scholars have constructed three key concepts: cultural basis, relationships, and growth paths. (Kaplan,1984). Each one highlights a crucial aspect of women's growth. The relevance of a woman's social surroundings is implied by her cultural background. The second, relationships, emphasizes the significance of relationships as a major organizing component of a woman's growth. The third, development routes, reveals that women respect relationships as a source of strength, which can result in a better sense of self development (Covington, 2007).

This, on the other hand, might have both positive and negative implications. Women who prioritize healthy relationships in their lifestyles are less likely to participate in misbehavior in able to preserve their relationships intact. In the criminal justice system, however, the opposite is true for a lot. Female recidivism and how it contrasts from male recidivism can be better understood through understanding relational theory. As they're more attentive 
to them, women's pathways into crime usually revolve around toxic marriages, such as abusive love partners. This could also be attributed to a lack of relationships, the death of many loved ones, or childhood sexual abuse.(Covington, 2007). Miller coined the term "condemned isolation" in her later work (1990). This is a term for when a woman perceives she is the cause of friction in her important relationships.( Miller et al., 1990).

\subsection{Research Methodology}

The descriptive research design was used in this study. The decision to choose a descriptive research methodology was influenced by Mugenda's (2008) observation that data was obtained using one or more relevant methods, such as surveys, interviews, and focus discussion groups, on a significant number of respondents utilizing this study design. In this regard, the study design was only focused on the canons of descriptive study design, namely, the explanation of the study's purpose and objectives.

Outside of Nairobi, the Western Region, which borders Uganda, is one of the former Kenya's seven administrative regions. It is located west of the Eastern Rift Valley and is primarily populated by Luhya people. Busia, Bungoma, Vihiga, and Kakamega are the four present counties that make up the region. The population of the region is estimated to be 4,334,202 people. Kakamega County is located in Kenya's old Western Province. Kakamega is the country's capital and largest city. Busia is a county in Kenya with a population of 1,660,651 people and a land area of $3,033.8 \mathrm{~km} 2$. It borders Kakamega County to the east, Bungoma County to the north, Lake Victoria and Siaya County to the south, and Busia District, Uganda to the west (GoK, 2010).

The study targeted population comprising of female recidivists and correctional officers in Kakamega, Busia and Bungoma women prisons, Kenya. A target population, as per the Sarantakos (1998), means all elements of an actual or imaginary group of people, events, or objects to which a study seeks to generalize its findings. The survey included 150 respondents from the women's prisons in Kakamega, Busia, and Bungoma.

Purposive sampling was used in the study to separate female recidivists from first-time offenders using official jail records. This is because not all female offenders in prisons were qualified as respondents for this study but only those ones who have been convicted more than once. The one hundred and fifty respondents were chosen at random from a total of two hundred and forty recidivists. The prison officers were also interviewed in the research study. The prison officers were able to provide information about rehabilitation programmes, facilities, causes of reoffending and the measures that should be implemented in order to reduce re-offending among female recidivists passing through their facility which is the key aim of the study. Purposive sampling enabled the researcher to employ only those aspects of the population that had been subjectively thought to have essential information for the study's aims (Mugenda \& Mugenda, 2003).

The study adopted methods that provided high accuracy, generalization of female recidivists and explanatory convenience (Borden et al., 2005). The respondents were asked to complete self-administered questionnaires by the researcher. To obtain in-depth information, important informants were interviewed using interview guides. Furthermore, rather of obtaining data from a statistically representative sample of the general population, the focus group discussion was utilized to acquire data from a purposefully selected group of individuals.

A pilot study was designed to test or try out a research instrument before it was used in a larger study (Baker, 1994). A pilot study is conducted to assist researchers in validating the study's questionnaire. A pilot study is a test of the instruments that will be utilized during the actual data collecting. This involves selecting 5\% of the sample size and administering the questionnaires to them. This helped the researcher to identify any ambiguous questions and rephrase them. The researcher also got an opportunity to clarify unclear instructions and improve other deficiencies in the questionnaires. The pilot study therefore was carried out in Kisumu women's prisons. The pilot study was conducted from $5^{\text {th }}-7^{\text {th }}$ May, 2019.

Validity refers to an instrument's capacity to measure what it was designed to measure. It refers to the magnitude to which an investigator is required to measure what he or she has set out to measure (Kumar, 2005). The instrument must be appropriate for the material as defined by the research objectives. Validity, according to Mugenda et al. (2012), is the accuracy and usefulness of inferences drawn from study findings. The content validity in the questionnaires was assessed by the investigator to ensure that the data acquired via the questionnaires sufficiently represented the domains of the variables being measured. According to Kumar (2005), content validity is the assessment of an instrument's ability to measure what it claims to measure, and it is primarily based on the logical link between the research instrument's questions and the study's objectives.

The degree to which a research generates consistent outcomes or data after repeated trials is known as reliability. Kumar (2005) defines dependability as a measure of an instrument's consistency, stability, predictability, and precision. He stated that the higher an instrument's uniformity and stability, the more reliable it is. The degree to which a measure is consistent in generating the same readings or findings when assessing the same thing at varying periods, according to Mugenda et al (2003). Test-retest method was used to ascertain reliability of the study questionnaire and Cronbach's Alpha Coefficient of reliability was computed and found to be 0.815 , which is higher that the threshold of 0.70 that is acceptable in behavioural sciences.

To assess quantitative data, the researcher used descriptive statistics. Descriptive statistics are indexes that 
are used to characterize a set of data (Mugenda \& Mugenda, 2003). Percentages and frequencies were employed as distribution measures. Means, modes, standard deviation, variance, percentages, and frequencies were used in the descriptive analysis. The total sample, age bracket, educational level, the offenders marital status, religion, history of imprisonment, and kind of offense were all used to analyze the sample. Statistical Packages for the Social Sciences (SPSS) version 20.0 for windows was used to analyze quantitative data.

\subsection{Study Findings}

\subsubsection{Demographic Characteristics}

Questionnaires were used to acquire demographic information on respondents. A total number of 150 questionnaires were distributed to responders, with 145 being completed and returned, As a result, there is a response rate of 97 percent. The demographic data was divided into categories as: marital status, religion, educational level and the age at the time of incarceration of female recidivists.

\subsubsection{Marital status}

The study's purpose was to learn more about woman recidivists' marital status. The results are shown in Figure 1 below.

\section{MARITAL STATUS}

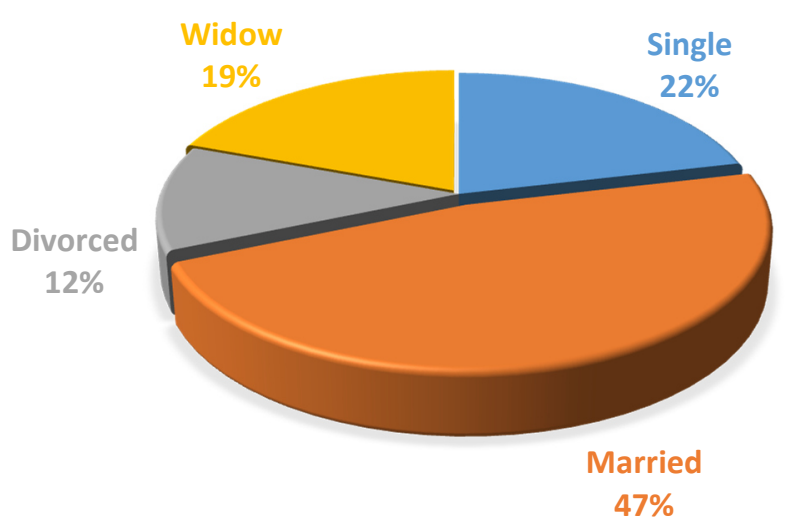

\section{Figure 1 Marital status of female inmates in Kakamega, Bungoma, Busia women's prisons}

\section{Source: Field Data (2019)}

The figure 1 above, shows that married female convicts accounted for 71(47\%), single female inmates for $32(22 \%)$, widowed female inmates for 29 (19\%), and divorced female inmates for 18 (12\%). Cumulatively, $80.7 \%$ of respondents are or had been in the institution of marriage when they committed a criminal offence. Determining the marital status of female was of significance in pre-determining the type and cause of offence committed regardless of their marital status. From the findings $12 \%$ who are now divorced had been divorced while in prison after committing a criminal offence.

This conclusion backs up the findings of Van voorhis et al,. (2010), who revealed that single moms make up the bulk of recidivists from over world. And as per the professional, the majority of single mothers in prison were divorced or widowed, with only a small percentage not married at the time of their incarceration.

\subsubsection{Religion}

The aim of the research was to examine which religious groups the women in Kakamega, Busia, and Bungoma's Main Prison were. Figure 2 depicts the data obtained. 


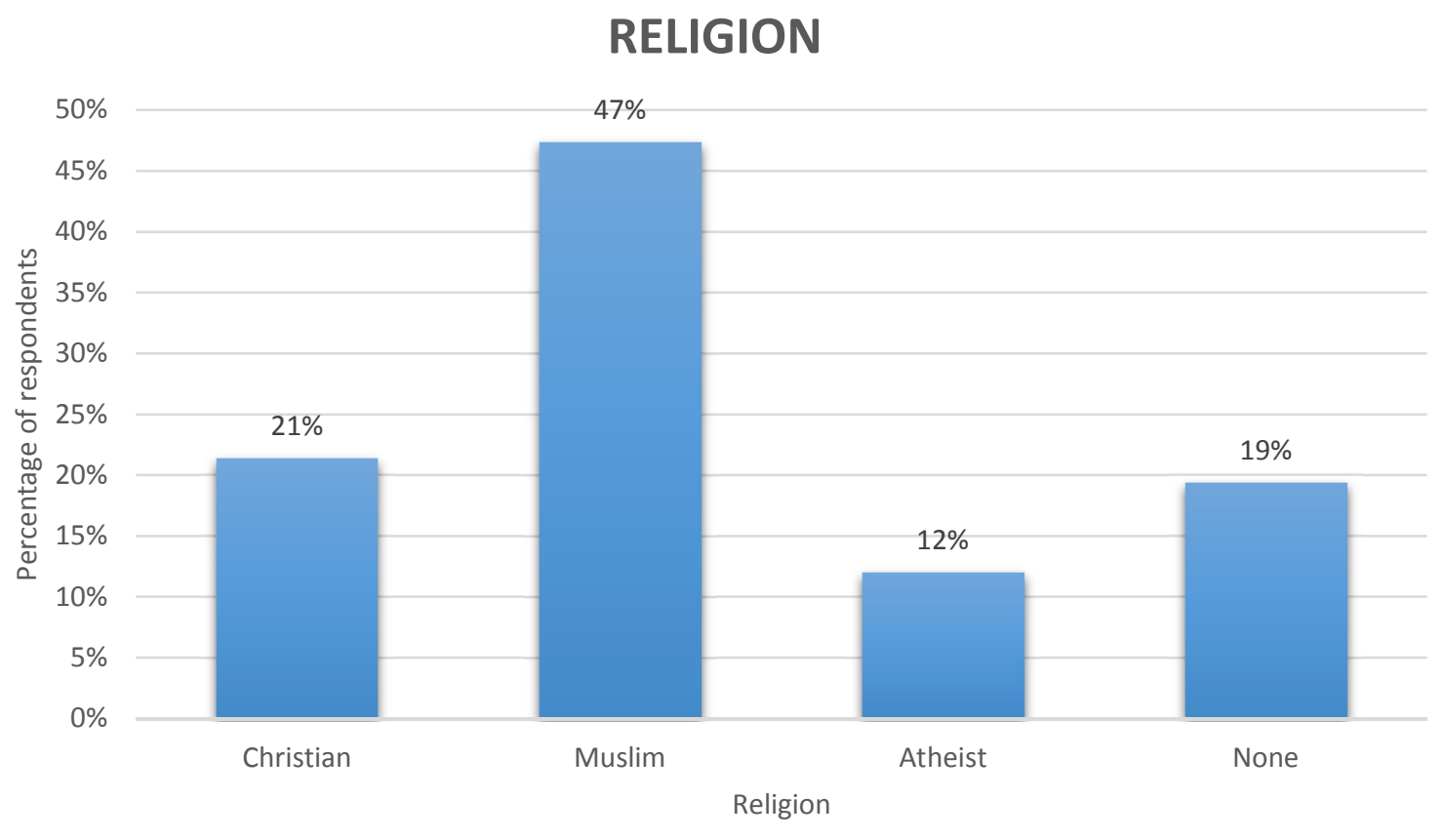

Figure 2 Religion of female respondents in Kakamega,Bungoma.Busia women's Prisons

Source: Field Data (2019)

As depicted from Fig 2, data obtained reveals that majority of the respondents were Muslims $71(47 \%)$ followed by Christians $32(21 \%)$ and Atheists $18(12 \%)$. Those who responded to having no religious affiliation constituted $29(19 \%)$ out of $145(100 \%)$ female inmates. These findings show that female Muslims have higher rate of recidivism (47\%) as compared to other religions with less than $25 \%$. It is probable that there is the relationship between involvement in crime and religion (Durant et al,.2017)

\subsubsection{Level of education of the respondents}

Respondents were required to indicate their educational levels. It was to assist to identify the educational background of the recidivists so as to determine the pattern that existed. Table 1 summarizes the findings.

Table 1: Educational Level

\begin{tabular}{|c|c|c|}
\hline Education & Frequency & Percentage (\%) \\
\hline Primary & 91 & $61 \%$ \\
\hline Secondary & 47 & $34 \%$ \\
\hline University & 2 & $1 \%$ \\
\hline Tertiary & 5 & $3 \%$ \\
\hline Total & 145 & 100.0 \\
\hline
\end{tabular}

The results as demonstrated in Table 1 indicates that, 91(61\%) had primary education, 47(34\%) had secondary, $5(3 \%)$ had tertiary while $2(1 \%)$ had university education. The fact that majority of the respondents $(61 \%)$ only managed to attain some primary education and $34 \%$ had attended secondary school is an indication of their socioeconomic profile which conduces to engagement in criminality.

According to the study results $61 \%$ with primary education had been incarcerated before. This group had the highest number of incarcerated inmates. The study further revealed that 47 respondents (34\%) with secondary education had been incarcerated before. The level of education was statistically significant in reducing recidivism. Prisoners who had education were less likely to commit crime than those with no or less education level.

The validity of these findings can be corroborated by a previous study done by Bernberg \& Krohn (2003), and Wang, Bloomberg, and Li (2005) which carried out an investigation on the impact of education level on prisoners' likelihood of repeating or engaging in crime after serving their sentences. The study noted that education empowered prisoners with literacy skills knowledge and insight to deal with life. Education also changed a person's perspective and provided insight on how to act and react in different situations but this did not reduce the chances of committing crimes.

According to a research by Howell (2003), inmates with a diploma level of education or higher are less likely to return to jail than those who do not. When senior inmates were compared to younger offenders, the effect was considerably stronger (Clements, 2004). Howell (2003) discovered that convicts who received proper education were less likely to reoffend than those who did not receive basic education. 
According to studies, convicts have much lower literacy skills than people in the general community (Greenberg, Dunleavy, Kutner, \& White, 2007). In addition, research has found a link between educational attainment and community recidivism (Brennan, Dieterich, \& Ehret, 2009; Horney, Osgood, \& Marshall, 1995; Jensen \& Reed, 2006; O'Connell, 2003; Ulmer, 2001). This research backs up the findings of Salibary (2007), who found that lower educational levels can lead to a lack of economic empowerment, which can lead to issues for women such as parental anguish and low self-esteem among female offenders. People with a greater level of education, on the other hand, develop a dialectic approach to reasoning that allows them to integrate contradictory positions and maybe prevent illegal action.

\subsubsection{Age of the respondents}

The age of the respondents was requested. The goal was to look at the trends of female recidivism in the women's prisons in Kakamega, Bungoma, and Busia. According to the findings, 33\% of the respondents were between the ages of 36 and 45 . Respondents aged 18-35 years old made up 37\% of the total, while those aged 46-55 years old made up 16\%. Respondents aged 55 and up made up 1.0 percent of the total. See table 2

Table 2 Age of female respondents in Kakamega,Bungoma,Busia Female Main Prison

\begin{tabular}{lcc}
\hline Age bracket & Frequency & Percentage $(\%)$ \\
\hline & & \\
$18-25$ & 18 & $12 \%$ \\
$26-35$ & 54 & $37 \%$ \\
$36-45$ & 47 & $33 \%$ \\
$46-55$ & 24 & $16 \%$ \\
Over 55 & 2 & $1 \%$ \\
Total & 145 & $100 \%$ \\
\hline
\end{tabular}

Source: Field Data (2019)

The study's findings revealed that out of 145 inmates, respondents between age of 18-25 years were $12 \%$, those between $26-35$ constituted $37 \%$ whereas respondents between age of 36-45 years, $46-55$ years and over 55 years constituted $33 \%, 16 \%$ and $1 \%$ respectively. This indicates that the majority of responders were between the ages of 26 and 35 (37\%). Findings revealed that respondents between 26-35years (37\%) were more likely to reoffend. The above findings resonates with other studies that have been conducted across the globe that found out that majority of female offenders are young and often in unloving relationships (Van Voorhis et al,.2010)

Conversely, the notion of relational psychological development links female criminality to mental illnesses including depression and self-destructive conduct as a result of unbroken relationships.

This study also found out that the incarcerated women in these selected counties in western region suffer from substance abuse which make them to be at disadvantage since the mood of treatment which is the clinical treatment is not being applied.

Given the findings, majority of female respondents were youthful and energetic members of the community and in their most productive years of building the nation hence it is worth undertaking a study to investigate how incarceration of such a group of people affects the country economic development.

\subsubsection{Patterns of Recidivism among Female Prisoners in selected Counties in Western Kenya Region Prisons}

The study focused on various patterns that the female recidivists exhibited during the research. The following tendencies are discussed: type of offense, number of times the offender had been imprisoned, and so on.

\subsubsection{Type of Offence}

The respondents were requested to list the types of offenses they were convicted of in the past. This was useful in determining the type of offence that most recidivists committed. The findings are depicted in the below. 


\section{Type of offence}

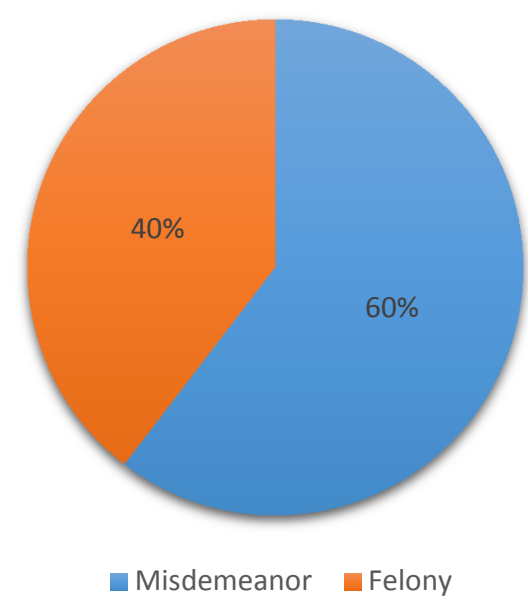

Figure 3: Type of Offence committed by the respondent

Majority $(60 \%)$ had misdemeanor offence as their main offence. These included offences like random vandalism. About $15 \%$ committed drug related offences such as drug peddling, trafficking, or using such drugs which are illegal.

Table 3 shows the different types of offenses that the offenders have committed.

\begin{tabular}{|c|c|c|c|c|c|c|c|c|}
\hline $\begin{array}{l}\text { First } \\
\text { conviction }\end{array}$ & Frequency & Percentage & $\begin{array}{l}\text { Second } \\
\text { conviction }\end{array}$ & Frequency & Percentage & $\begin{array}{l}\text { Third } \\
\text { conviction }\end{array}$ & Frequency & Percentage \\
\hline Murder & 50 & 33 & Murder & 21 & 14 & Murder & 19 & 12.6 \\
\hline Assault & 75 & 50 & Assault & 15 & 10 & Assault & 20 & 13 \\
\hline Arson & 30 & 20 & Arson & 10 & 6 & Arson & 12 & 8 \\
\hline $\begin{array}{l}\text { Brewing } \\
\text { of illegal } \\
\text { liquor }\end{array}$ & 101 & 67 & $\begin{array}{l}\text { Brewing } \\
\text { of illegal } \\
\text { liquor }\end{array}$ & 121 & 80.6 & $\begin{array}{l}\text { Brewing } \\
\text { of illegal } \\
\text { liquor }\end{array}$ & 127 & 84.6 \\
\hline $\begin{array}{l}\text { Child } \\
\text { neglect }\end{array}$ & 125 & 83 & $\begin{array}{l}\text { Child } \\
\text { neglect }\end{array}$ & 119 & 79.3 & $\begin{array}{l}\text { Child } \\
\text { neglect }\end{array}$ & 112 & 74.6 \\
\hline Robbery & 71 & 47 & Robbery & 19 & 12.6 & Robbery & 9 & 6 \\
\hline Stealing & 97 & 64 & Stealing & 83 & 55.3 & Stealing & 89 & 59.3 \\
\hline
\end{tabular}

Source: Field Data (2019)

The findings in table 3 reveal that offenders committed murder (33\%), assault (50\%), brewing of illegal liquor $(67 \%)$, child neglect (83\%) and stealing (64\%) as first conviction. During the second conviction, brewing of illegal liquor $(80.6 \%)$, child neglect $(79.3 \%)$ and stealing $(55.3 \%)$ while third conviction the offenders committed brewing of illegal liquor $(84.6 \%)$, child neglect $(74.6 \%)$ and stealing $(59.3 \%)$. The findings show that most recidivists have been convicted mostly with illegal brewing of liquor and the trend has been continuing for a long period. Majority of the recidivists' respondents has been rearrested because of illegal liquor, child neglect and stealing. The trend is too high for the illegal brewing of liquor, child neglect and stealing. According to the interview with key informants, it revealed that most recidivists commit crimes such as stealing, murder, brewing of illegal liquor and child neglect. Most offenders recidivate based on misdemeanor. The researcher further investigated number of times the offender had been convicted. Table 4.4 demonstrates the findings

Table 4 Number of times respondent had been imprisoned

\begin{tabular}{lllll}
\hline How many times have you been imprisoned & & & \\
\hline & Frequency & Percent & Valid Percent & Cumulative Percent \\
\hline Twice & 115 & 58.7 & 86.3 & 86.3 \\
Thrice & 18 & 4.0 & 5.9 & 92.2 \\
More than thrice & 12 & 5.3 & 7.8 & 100.0 \\
Total & 145 & 68.0 & 100.0 &
\end{tabular}

\begin{tabular}{lll}
\hline Total & 145 & 100.0 \\
\hline Source: Field Data $(2019)$ &
\end{tabular}

Source: Field Data (2019)

According to the results, the most of responders had been imprisoned twice $115(58.7 \%)$, more than thrice $12(5.3 \%)$, and thrice were $18(4.0 \%)$. The findings found out that the respondents that most recidivists have been 
convicted twice mostly with illegal brewing of liquor and the trend has been continuing for a long period. Majority of the recidivists' respondents has been rearrested because of illegal liquor, child neglect and stealing.

The results of these findings of this study are consistent with those of other studies that show a growing worry about recidivism among female criminals around the world. Deschenes, Owen, and Crow (2007), for example, cited the findings of a research conducted in US women's correctional facilities, which revealed that 58 percent of jailed women had previously served time in prison.

Table 5: Correlation between demographic factors and recidivism

\begin{tabular}{|c|c|c|c|c|c|c|c|}
\hline & & & & Recidivi & & & \\
\hline \multirow{3}{*}{ Age } & $\begin{array}{l}\text { Pearson } \\
\text { Correlation }\end{array}$ & 1 & .810 & $.286^{* *}$ & .048 & .104 & .154 \\
\hline & Sig. (2-tailed) & & .324 & .000 & .559 & .206 & .091 \\
\hline & $\mathrm{N}$ & 150 & 150 & 150 & 150 & 150 & 121 \\
\hline \multirow{3}{*}{$\begin{array}{l}\text { Have you been } \\
\text { imprisoned } \\
\text { prior to your } \\
\text { current } \\
\text { imprisonment }\end{array}$} & $\begin{array}{l}\text { Pearson } \\
\text { Correlation }\end{array}$ & .810 & 1 & $-.399^{* *}$ & $.206^{*}$ & .093 & .065 \\
\hline & Sig. (2-tailed) & .324 & & .000 & .012 & .257 & .480 \\
\hline & $\mathrm{N}$ & 150 & 150 & 150 & 150 & 150 & 121 \\
\hline \multirow{3}{*}{ Status } & $\begin{array}{l}\text { Pearson } \\
\text { Correlation }\end{array}$ & $.286^{* *}$ & $-.399^{* *}$ & 1 & $-.229^{* *}$ & $-.161^{*}$ & .015 \\
\hline & Sig. (2-tailed) & .000 & .000 & & .005 & .049 & .869 \\
\hline & $\mathrm{N}$ & 150 & 150 & 150 & 150 & 150 & 121 \\
\hline \multirow{3}{*}{ Religion } & $\begin{array}{l}\text { Pearson } \\
\text { Correlation }\end{array}$ & .048 & $.206^{*}$ & $-.229^{* *}$ & 1 & $.238^{* *}$ & -.101 \\
\hline & Sig. (2-tailed) & .559 & .012 & .005 & & .003 & .271 \\
\hline & $\mathrm{N}$ & 150 & 150 & 150 & 150 & 150 & 121 \\
\hline \multirow{3}{*}{ Education } & $\begin{array}{l}\text { Pearson } \\
\text { Correlation }\end{array}$ & .104 & .093 & $-.161^{*}$ & $.238^{* *}$ & 1 & $-.256^{* *}$ \\
\hline & Sig. (2-tailed) & .206 & .257 & .049 & .003 & & .005 \\
\hline & $\mathrm{N}$ & 150 & 150 & 150 & 150 & 150 & 121 \\
\hline \multirow{3}{*}{$\begin{array}{l}\text { Did you secure } \\
\text { a job after } \\
\text { release from } \\
\text { prison }\end{array}$} & $\begin{array}{l}\text { Pearson } \\
\text { Correlation }\end{array}$ & .154 & .065 & .015 & -.101 & $-.256^{* *}$ & 1 \\
\hline & Sig. (2-tailed) & .091 & .480 & .869 & .271 & .005 & \\
\hline & $\mathrm{N}$ & 121 & 121 & 121 & 121 & 121 & 121 \\
\hline
\end{tabular}

**. Correlation is significant at the 0.01 level (2-tailed).

*. Correlation is significant at the 0.05 level (2-tailed).

Table 5 shows that different demographic characteristics have a statistically significant impact on recidivism. With $\mathrm{r}=.810$ at $\mathrm{P}<0.05$, it was determined that more young people were more prone to recidivate than their older counterparts. This indicates that a growing number of young people are focusing their energies towards criminal activity. This conclusion on age corresponds to another finding in a study by Farrington (2012), who discovered that the younger a person is, the more likely they are to conduct a series of crimes, even if they have already been convicted of multiple other crimes for similar or different offenses.

Education level, marital status, religion, and employment all had at $.606(\mathrm{P}<0.05), .869(\mathrm{P}<0.05), .559(\mathrm{p}<0.01)$ and $.554(\mathrm{P}<0.05)$ association with recidivism, respectively. As a result, more educated persons are less prone to recidivate than those who are less educated or uneducated. These results on education and employment is consistent with Janku's (2019) findings, which revealed that education, marital status, and employment status all increase recidivism among people of different age.

\section{Conclusions}

The results revealed that recidivism is linked to the existence of several factors, including prison rehabilitation programs, the impact of environmental to which prisoners are exposed while incarcerated, the level of socioeconomic status of ex-offenders immediately upon release, and the essence of ex-convicts' welcome from the community after their release from the prison. The study therefore concludes that most of the ex-offenders have low educational level and had been imprisoned more than thrice.

\section{Recommendations}

The following are some recommendations based on the preceding discussions:

To reduce the rates of crime in society, the government should address the rising trend of female recidivism. The government should address the core causes of crime in society by guaranteeing that the use of violence as a means of resolving personal issues requires social responsibility. 
The rehabilitation programs offered within the prison should be need centred and interest based covering the holistic approach. Special training for prison officials should be provided with the goal of meeting the demands of female inmates. In order to properly implement the rehabilitation programs and reduce the rates of female recidivism, prison personnel should be taken to trainings and workshops for short courses. Furthermore, the GK jails should get new modernized technology and tools that provide necessary skills, resulting in effective rehabilitation programs and lowering female recidivism.

\section{REFERENCES}

Agnew, R. (2011). Control and disorganisation theory. In C. D. Bryant (Ed.), The Routledge handbook of deviant behaviour (pp. 114-120). New York: Routledge.

Alper M, Durose MR, Markman J: 2018 update on prisoner recidivism: a 9-year follow-up period (20052014).2018

Amnesty International. (2015). The state of the world's human rights: Amnesty international report 2014/2015. London, UK

analysis. International Journal of Offender Therapy and Comparative

Andrew, Nancy, 2009, Reforming South Africa's land system: the conflict that won't go away, (French \& English) Institut français des relations internationales (IFRI), Paris:

Andrews, D. A., \& Bonta, J. (2003). The psychology of criminal conduct (3rd ed.).

Barlow, J., Smailagic, N., Huband, N., Roloff, V., \& Bennett, C. (2014). Group-based

Baumeister, R. F. (1997). Esteem threat, self-regulatory breakdown and emotional

Beck , A. J. , \& Harrison, P. M. ( 2008 ). Sexual victimization in state and federal prisons reported by inmates, 2007 . Washington, DC : Bureau of Justice Statistics

Behavior, 36, 541-566.

Benda, B. B. (2005). Gender differences in life-course theory of recidivism: A survival analysis. International Journal of Offender Therapy and Comparative Criminology, 49, 325-342.

Analysis. International Journal of Offender Therapy and Comparative Criminology, Vol. 49, No. 3, pp. 325-342.

Caddle, D. and Crisp, D. (1997) Imprisoned Women and Mothers. Home Office Research Study Number 162, London: Home Office

Celik, H., (2008). A sociological analysis of women criminals in the Denizli open prison,

Center for Criminal Justice Research

Chesney-Lind, M., \& Shelden, R, G (2004). Girls, delinquency, and juvenile justice (3rd

Cincinnati, OH: Anderson.

Covington, S. (2007). The relational theory of women's psychological development:

Covington, S. S., \& Bloom, B. E. (2006). Gender-responsive treatment and services in correctional settings. Women and Therapy, 29 (3/4), 9-33.

Giordano, P. C., Cernkovich, S. A. \& Rudolph, J. L. (2002). Gender, crime, and desistance: Towards a theory of cognitive transformation. American Journal of Sociology, Vol. 107 (No. 4), pp. 990-1064.

Glenwick, D. S. (2016). Handbook of methodological approaches to community-based research: Qualitative, quantitative, and mixed methods. Oxford University Press.

Goffman, E. (1963). Stigma: Notes on the management of a spoiled identity. Englewood Cliffs, NJ: Prentice Hall

Government of Kenya, 2019 on Statistics on Women and the Criminal Justice System

Government of Kenya. (2015). Prisons Act. Nairobi: government Printers.

Greenfield, L., \& Snell, L. (1999). Women offenders. (NCJ Publication No. 175688). Washington, DC: Bureau of Justice Statistics.

Harrison , P. M. , \& Beck , A. J. ( 2006 ). Prisoners in 2005 (NCJ No. 215092) . Washington , DC : Bureau of Justice Statistics

Hennink, Monique M. 2007. International focus group research: a handbook for the health and social sciences. Cambridge: Cambridge University Press.

Holtfreter, K., \& Morash M. (2008). The needs of women offenders. Women \& Criminal

Huebner, D. (2012). The lure of the transcendent: Collected essays by Dwayne E. Huebner. Routledge.

Kothari, C. (2008). Research Methodology, Methods and Techniques. New Delhi: New age International Publisher Kruttschnitt, C., \& Gartner, R. (2003). Women's imprisonment. Crime and Justice: A

Kumar, R. (2011). Research Methodology, Methods and Techniques. New Delhi: New age International Publisher Kumar, R. (2005). Research methodology: A step-by-step guide for beginners. SAGE.

La Vigne, N. G. , Visher, C. , \& Castro , J. ( 2004 ). Chicago prisoners' experience returning home . Washington, DC : Urban Institute

La Vigne, N. G. \& Mamalian, C. A. (2004). Prisoner reentry in Georgia. Washington, DC: The Urban Institute

Langan, P., \& Levin, D. (2002). Recidivism of prisoners released in 1994. Washington, DC: U.S. Department of Justice 
Miller, JB. “Connections, Disconnections and Violations.” In Work In Progress. Work In Progress 33. Wellesley, MA: Stone Center, 1990

Miller, T. W. (2012). undefined. ABC-CLIO.

Miller-Warke, J. (1999). Report on women's custodial corrections. Western Australia:

Ministry of Justice.

Mugenda, A. G., \& Mugenda, O. M. (2008). Research methods: Quantitative and qualitative approaches. Nairobi: Acts Press.

Murugi, G. M. (2012). Incarcerated women: Kenya correctional and rehabilitation National Institute on Drug Abuse. (2018). NIDA modified-ASSIST. Retrieved October 20, 2018.

Sekaran, U. (2006). Research methods for business: A skill building approach, 4Th ed. John Wiley \& Sons.

Valentine, E. J., \& Redcross, C. (2015). Transitional jobs after release from prison: Effects on employment and recidivism. IZA Journal of Labor Policy, 4(1). https://doi.org/10.1186/s40173-015-0043-8

Van der Velden, P. G., \& Van der Knaap, L. M. (2016). undefined. Clinical Psychological Science, 5(1), 141145. https://doi.org/10.1177/2167702616654906

Wekesa, E. (2013). The role of prisons in administration of custodial rehabilitation of inmates in Kenya: A case study of Thika main prison, Kiambu, County (master thesis). Kenya: Kenyatta University.

Wittenburg, K. B., \& Weitzman, L. M. (1998). Relational grammars: Theory and practice in a visual language interface for process modeling. Visual Language Theory, 193-217. https://doi.org/10.1007/978-1-46121676-6_6

Xu, L., Wang, X., Pan, X., Wang, X., Wang, Q., Wu, B., Cai, J., Zhao, Y., Chen, L., Li, W., \& Li, J. (2020). Education level as a predictor of survival in patients with multiple myeloma. https://doi.org/10.21203/rs.3.rs18271/v1 